per man and 3.42 per woman in those over $65 .^{2}$ Half of the disability in their series was considered unknown to the doctor as compared with $20.5 \%$ in our series. Most of the disability in both series was slight or moderate but early diagnosis is good diagnosis and more likely to lead to arrest or cure, or to prevent the vicious circles of morbidity to which the elderly are prone. We were surprised at the low incidence $(20.5 \%)$ of unknown disability in our 70- to 72-year-olds. The definition of "unknown" in this context is debatable. A doctor may be fully aware of a patient's obesity without recording it on his N.H.S. medical file, though no doubt he should.

By the age of 70 the ranks of the men have been thinned out by killing diseases and women outnumber men by three to two. Myocardial infarctions have taken their toll and heart disease is now equally distributed in the sexes, but $25 \%$ of the men have demonstrable peripheral vascular disease and another $25 \%$ have chronic bronchitis as compared with $9 \%$ and $7 \%$ respectively of the women. The most urgent need in prophylactic geriatrics is for more research into the pathology and prevention of degenerative disease.

\section{HEALTH SCREENING}

Community health screening of the elderly may be very timeconsuming and expensive in money and personnel. MacLennan comments that a simplified technique is necessary for general practice conditions and that the initial screening could be done by a health visitor, who would detect patients in need of referral to the general practitioner or to a clinic for examination. ${ }^{12}$ But Donald points out that there is only one health visitor for 3.6 general practitioners in Britain and were they all attached to general practice their time could be fully occupied with caring for the young (a statutory duty) leaving no time for the elderly. ${ }^{13}$ Indeed, Ness and Reekie conclude that screening of the elderly would require one additional whole-time health visitor or nurse per four general practitioners. ${ }^{14}$ This was also our experience: the task was beyond the capability of three doctors and one health visitor but became practicable with the help of another full-time nurse. Andrews et al. argue that screening is necessary because of late reporting of illness by older people and this view cannot be challenged, ${ }^{15}$ but in our experience older people seldom conceal their illnesses deliberately and they are very willing to reveal their health problems to those they trust if given the opportunity. In other words, failure of self-reporting means failure to make contact with the elderly and failure to ask the right questions. The busy general practitioner has neither the time for routine visiting of the elderly nor the training for psychosocial investigation in depth and this work is far better done by a health visitor. She may be hard pressed for time and may require another nursing colleague but her very presence in a health team will reduce the reservoir of unreported illness, and if she is given a well thought-out check list which is not cumbersome very little morbidity will be missed.

\author{
References \\ 1 Anderson, W. F., and Cowan, N. R., Lancet, 1955, 2, 239. \\ Williamson, J., Stokoe, I. H., Gray, S., Fisher, M., Smity, A., McGhee, \\ A., and Stephenson, E., Lancet, 1964, 1, 1117. \\ 3 Milne, J. S., Hope, K., and Williamson, J., fournal of Chronic Diseases, \\ 1970, 22, 805. \\ ${ }^{4}$ Williamson, J., Gerontologia Clinica, 1967, 9, 236. \\ 5 Williams, E. I., Bennet, Frances M., Nixon, J. V., Nicholson, M. Rosanel, \\ and Gilbert, Jean, British Medical Fournal, 1972, 2, 445. \\ 6 Williamson, J., Modern Geriatrics, $1970,1,24$. \\ 7 Milne, J. S., Maule, M. M., and Williamson, J., British fournal of Pre- \\ ventive and Social Medicine, 1971, 25, 37. \\ 8 Akhtar, A. J., Gerontologia Clinica, 1972, 14, 205. \\ 9 Pridie, R. B., Gut, 1966, 7, 188. \\ 10 Player, D. A., Irving, G., and Robinson, R. A., Health Bulletin, 1971, 29, \\ 105. \\ 11 Gibson, Iris I. J. M., and O'Hare, Margaret M., Gerontologia Clinica, \\ $1968,10,271$. \\ 12 McLennan, W. J., Modern Geriatrics, 1973, 3, 253. \\ 13 Donald, A. G., Update, 1971, 1, 305. \\ 14 Ness, Mary J., and Reekie, Mary M., Nursing Times, 1970, 66, 39, 1232 \\ 15 Andrews, G. R., Cowan, N. R., and Anderson, W. F., Problems and \\ Progress in Medical Care, ed. by G. Maclachlan. London, Oxford \\ University Press, 1971.
}

\title{
Around Europe
}

\section{Clinical Medicine and Research in Germany}

\author{
D. N. S. KERR
}

British Medical fournal, 1974, 2, 111-114

Last year the British Council began sponsoring a series of visits to our European partners to learn more about their schemes of medical training and research to see whether interchange with Great Britain could be made easier. Dollery and Burn $^{1}$ described the first visit to France, and in December 1973 I made a trip to West Germany and spent two weeks visiting 24 institutions, interviewing 40 individuals from a medical student at Bonn to the Rector at Cologne and chatting to many others as I toured the universities, research institutes, and hospitals. My itinerary was arranged by the Cologne office

Department of Medicine, University of Newcastle upon Tyne

D. N. S. KERR, M.SC., F.R.C.P., Professor of Medicine

of the British Council with the advice of the German Research Society. Everywhere I was met with unfailing punctuality, courtesy, and hospitality. My ineptitude at German was more than compensated by the excellent English of my German hosts and by the skill of British Council staff as interpreters.

\section{Medical Education}

The pathway to a medical career is summarized in the table. Applications for a place in medical school are about as numerous in West Germany (population $60 \mathrm{~m}$.) as in Great Britain (population $55 \mathrm{~m}$.) but twice as many places are offered6,400 in 27 medical schools. After a brief unhappy experience of unlimited entry to medical school, numbers were restricted and competition is stiff; the selection is made without interview through a central clearing house and is based largely on performance in the "Abitur"-the final examination at high 


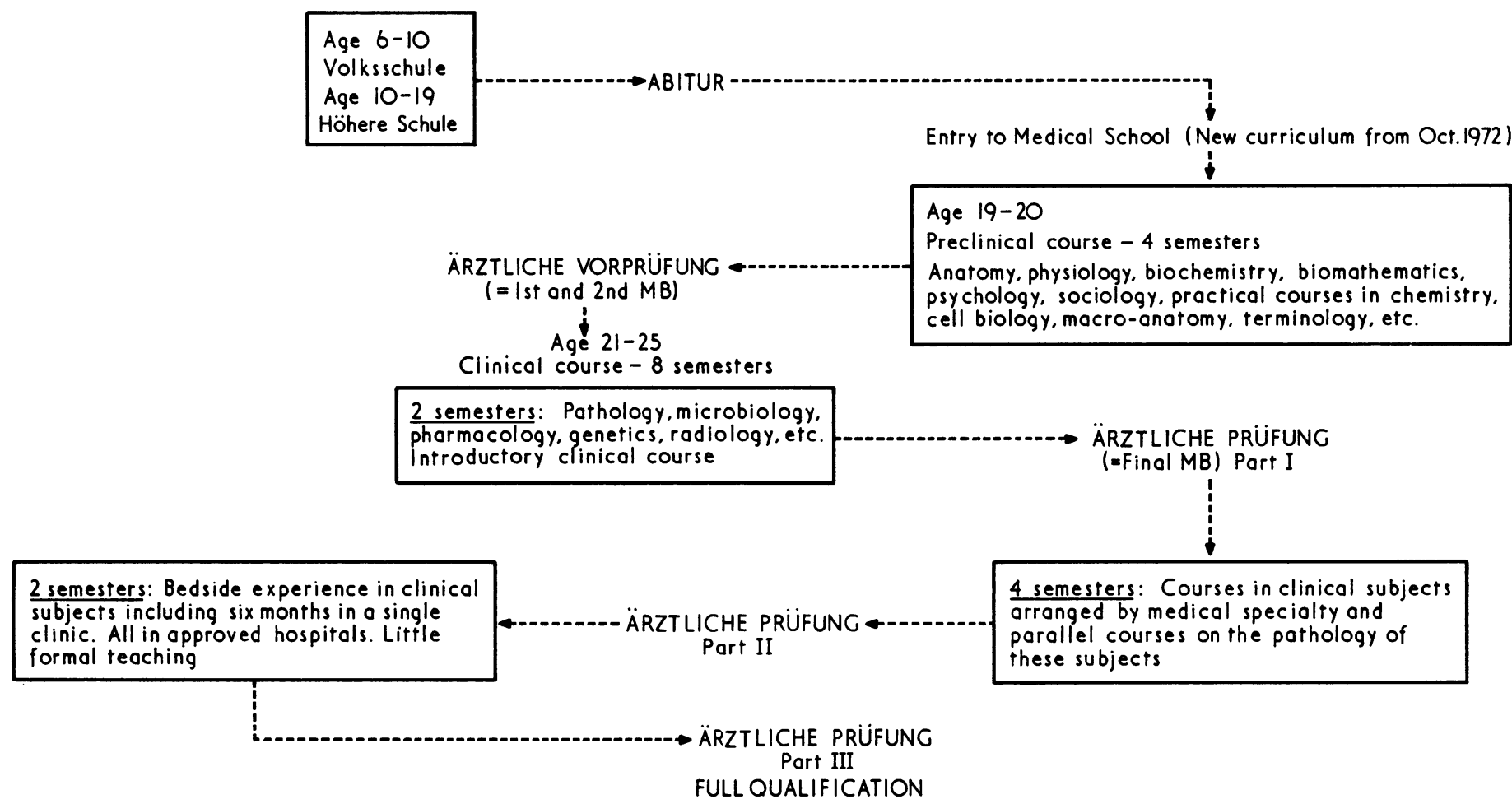

school, roughly our A levels. A recurring complaint of German teachers is that student numbers are much too large. Living accommodation has not been built to cope with the expansion, there is no collegiate structure to provide small group loyalty, and none of the universities I visited has a tutorial system. Seminar and bedside teaching cannot be developed as far as most teachers would like and I gained the impression that contacts between staff and students were not as close as in this country.

Nevertheless, there is one big compensation. About $90 \%$ of German doctors take their M.D. The thesis they write varies greatly from the equivalent of a student research project in Britain to something approaching a Ph.D. The research work, often done part time during undergraduate studies, typically takes about one year during which the student works closely with the members of his chosen department. He usually has an immediate supervisor who spends several hours a week with him and he meets the staff regularly at M.D. seminars.

In October 1973 a new unified system of medical education was introduced throughout the Federal Republic. German teachers are therefore coping with a problem familiar in this country-running two dissimilar curricula side by side. The old curriculum has three clinical years and is followed by a twoyear internship. The new curriculum shown in the appendix has four clinical years, the last of which is similar to the final year in many British universities-an almost full-time apprenticeship with few lectures-and the internship is abolished.

Under the new scheme oral examinations will be abolished and all tests will be written as multiple choice questions (M.C.Q.). An institute has been founded at Mainz, with an annual budget of over $£ 3$ million to plan the new curriculum. Questionnaires were sent to every professor and committees hammered out lists of essential topics in each discipline. These have now been published in a book available to students. Compulsory lectures have been abolished so the student who prefers to browse in the library can now do so with the assurance that he is not missing vital clues to the examination questions. Attendance is still required at some practical classes and clinical courses. At Mainz a vast library of M.C. questions has been amassed. Two to three thousand questions have been collected for major disciplines, agreed and graded from easy to very difficult. Examinations will be drawn up from these graded questions, answered on lector sheets, and marked by computer. Some teachers fear that the results of this nationwide objective examination will be used to make odious comparisons between universities and pressurize them into changing their educational methods. It is difficult to believe that their fears are groundless, but perhaps it will bring more benefits than harm.

Many German students receive undergraduate grants of about 500 D.M. per month (about $£ 1,000$ per annum). This may seem generous to Britons but with accommodation to rent on the open market and with German prices it will not qualify them for the jet set. They are offered a very varied educational fare. All departments provide optional lectures-about four times as many as the average student attends-and spread them over the day from dawn till dusk. Many of these lectures are also attended by students of science, dentistry, social study, etc.

The failure rate in medicine is low-perhaps $5 \%$ at 1 st M.B. and $10 \%$ for overall drop-out rate. Failure at final M.B. is rare. There was speculation about the effect of the new objective tests on performance and failure rate.

\section{University Organization}

The old power structure-in which the head of department (paradoxically known as the "Ordinarius") was all powerful, hired and fired his staff, approved the training of his assistants, negotiated his budget direct with the government, and monopolized the private practice-is breaking down everywhere but remnants of it remain in the conservative universities. Private practice fees are now subdivided among clinical staff. The Ordinarius in a conservative university still appoints his staff and is largely responsible for their promotion. The rector is elected for one year only with a maximun of one extension and deans also have limited tenure. Consequently the professors and the permanent administrative staff headed by the Kanzler (a civil servant appointed by the State) have greater power than in British universities. In some universities and their associated hospitals a pattern much closer to our own is emerging with a divisional structure reminiscent of Cogwheel and participation of junior academics, students, and technical staff in all university committees. These reforms are being hastened by the establishment of a "Combined Institute of higher Education" (Gesante 
Hochschule) in many cities which previously had a separate university, teacher training college, polytechnic, etc.

\section{Postgraduate Education}

After qualification a German doctor may complete his M.D. on a graduate grant or as a paid assistant in the appropriate department. Preclinical departments often have unfilled posts for assistants that can be used in this way. The two-year internship, which is compulsory at present, includes six-month periods of medicine, surgery, and obstetrics. Some German doctors therefore go abroad, particularly to the United States, to receive the more varied training offered in internships there. If he plans to specialize, as most German doctors do, the fully qualified doctor must now seek a place in a training programme, usually in a university or teaching hospital. In oversubscribed specialties such as internal medicine he may have to wait a year or two and may be asked to spend this time in research in Germany or abroad in return for a promise of a place at the end. Here the power of the Ordinarius to promise an appointment is useful. Organizations which finance research scholarships expect that the scholar will be offered a post at the end and this is proving difficult in those universities where appointment must be approved by an ultra-democratic committee.

In some specialties such as anaesthetics where there is a great unsatisfied demand for specialists, training is predominantly clinical and at the end of four to six years the trainee expects to walk straight into an attractive post as specialist in a large hospital. In older disciplines he will more often stay for a longer period in his university post and seek academic advancement. His career prospects are dominated by his prowess at research. One professor I spoke to felt that this emphasis on research was unhealthy. Excellent clinicians with no aptitude for research could not gain promotion to the post of Oberartz, which brings responsibility for patients (though under a nominal professorial control unfamiliar in Great Britain), and were lost to the teaching hospitals.

The doctor who does succeed in research aims to gain the academic accolade of "Habilitation," which gives him the title of Privat dozent and the right to deliver lectures in public. The process is a survival of the middle ages. After he has published around 20 papers, he produces a thesis embodying more work than his original M.D. and discusses it with his professor until the latter is satisfied that it has a more than sporting chance. His sponsor then introduces the name of the assistant at the end of a faculty board meeting. After this the candidate has to visit every professor in the faculty to discuss his research work and interests. A first secret ballot is then taken at academic board. The thesis is now read by two referees and circulates round the whole faculty with their comments. A second ballot is taken. If he is successful the candidate suggests several topics on which he could give a lecture. One is chosen, he is given brief notice, and must deliver the lecture without notes to the faculty, which solemnly takes its final ballot. This last part of the ceremony is derived from the old German and Scandinavian custom of defending the thesis but has been changed to give at least a token acknowledgement that teachers should be able to teach. Once he joins the faculty in this manner the German academic doctor is part of a "pack" that holds firmly together. It is still common for German professors (though not for students) to move from university to university, finishing at Munich-which has replaced Berlin as the largest and most prestigious-and they often take their assistants with them.

\section{Organization of Research}

Research in West Germany is almost synonymous with laboratory research. Study of the natural history of disease and controlled trials of therapy are regarded as inferior pastimes and the research potential of provincial hospitals is unexploited. On the other hand, laboratory-based research in universities and special institutes is furnished on a grand scale. One professor liked his assistants to travel abroad so that they learned how lucky they were at home. I brought back a kaleidoscopic impression of new buildings sprouting everywhere, massive institutes, lavish equipment, generous laboratories, computers in plenty, and first-class office accommodation. A civilized feature of most German offices is a large coffee table surrounded by armchairs, in which the visitor is entertained over coffee without the interposition of the professorial desk. Architects are given a freedom unknown in Britain and have embelliched every self-respecting research institute with a large marble entrance hall bedecked with tropical flowers, which is not converted to extra laboratories as it would be in Britain.

To a Briton, schooled in the Cavendish tradition that all good research is done in converted broom cupboards, the German laboratories seemed almost eerie in their quietness and underpopulation. Bench space is underused by our standards, yet I was told several times that shortage of space would be one of the main limitations to the acceptance of research fellows from abroad. One professor who said this to me had a department five times as large as mine with less than twice the staff. Technicians are not so liberally supplied and are hard to recruit even when money is available; most of them do a two-year full-time educational course rather than training on the job. I was told that most basic research departments expected to provide one technician per graduate worker but clinical departments were often well below this ratio; medical research workers often do their own technical work or suborn technicians who are really provided for service work into doing it.

A fortnight's tour leaves plenty of scope for sampling error but it was my impression that university staff provision was more generous than in Britain. For instance, a department of nuclear medicine had 13 professional staff and was able to employ most of its research workers in paid university posts with a reasonable salary. Nevertheless, much research money is also fed into university departments and research institutes from outside sources, notably the German Research Society (Deutsche Forschungsgemeinschaft: D.F.G. ${ }^{3}$ ). This is the nearest German equivalent to the M.R.C., but it is a nongovernmental body distributing private funds as well as federal and state contributions and it does not run its own institutes as the M.R.C. does. About a third of its budget goes on the "normal programme" of project grants-very similar to M.R.C. project grants-travel grants, training scholarships, and equipment grants. The remainder is disbursed into special institutions, in individual grants for computers and other large items of equipment, and in two ways peculiar to West Germany.

\section{PRIORITY RESEARCH PROGRAMMES (SCHWERPUNKTPROGRAMM)}

Areas in which research is urgently needed or likely to prove unusually productive are designated by the Senate of the D.F.G. on advice from its officers and various outside bodies. The selected areas are publicized and scientists apply to join a priority programme. The successful applicants receive financial support for several years and are expected to co-operate in avoiding overlap in their research. In small areas such as the aetiology of multiple sclerosis or the design of artificial organs, which affect only two or three cities, this must be quite straightforward, but in a topic such as environmental pollutants collaboration is demanded among 27 scientists in 14 cities scattered all over the Federal Republic. Other subjects receiving special attention include reproductive physiology and population control, membrane physiology, and the mode of action of hormones.

\section{SPECIAL RESEARCH AREAS (SONDERFORSCHUNGSBEREICHE)}

Universities are invited to select areas of research in which they 
are particularly successful, spreading across disciplinary boundaries, for special financial support, to be shared between the collaborating departments. The sums concerned are largeup to $£ 500,000$ per annum or more for a single university-and the collaborative group is given considerable freedom in how it spends the money.

The D.F.G. was founded in 1949 and since then its growth has been almost exponential. The annual budget was about $£ 60 \mathrm{~m}$. per annum in 1971 and is still rising fast. Several independent organizations such as the Volkswagen and Thyssen Foundations finance research to the tune of over $£ 20 \mathrm{~m}$. per annum and the von Humboldt Foundation expends about $£ 2 \mathrm{~m}$. per annum on scholarships for foreign research workers and students coming to Germany. In all these instances the money is spread over many disciplines, but apparently the amount devoted to medicine is somewhat larger than in Britain.

\section{MAX PLANCK INSTITUTES}

Research is increasingly a job for full-time professionals. Germany recognized this fact in 1911 by founding the Kaiser Wilhelm Gesellschaft for full-time research. It was refounded in 1948 and renamed after a famous German physicist. There are 51 institutes, about a third of them devoted to medicine; their nearest equivalents in this country are the M.R.C. units. The Max Planck Institutes are financed directly by the federal and state governments, which provide $90 \%$ of the funds, but they can also solicit support from outside. Institutes are often built around one man of outstanding merit-the Max Planck Institutes provide over half of Germany's Nobel prizewinnersand may be closed down when he retires. This saves the organization from being lumbered with buildings, men, and ideas that have passed their productive peak, but it also implies uncomfortable insecurity of tenure.

One of the privileges of working in a Max Planck Institute is the right to invite distinguished foreign scientists to work on a stipend (around $£ 4,000$ per annum) during their sabbatical year, and about a sixth of the total staff of 4,000 employed in the institutes are overseas visitors. One whole British research group has recently moved in this way to West Germany but the facility is more frequently enjoyed by Americans.

\section{Interchanges}

Paid sabbatical leave is almost as rare in West Germany as in Britain. Many German doctors speak English well enough to benefit from clinical training here and some would like to come, but opportunities are limited by our need to advertise all N.H.S. posts and by a salary differential which is accentuated by the German's need to maintain his social security payments at home. A senior registrar salary is the least which is likely to attract even a dedicated German to Great Britain. Two-way exchanges are more feasible but are hampered by the shortage of British doctors fluent in German. For the immediate future the most significant form of interchange-living and working in another country-is likely to take place at research fellow level.

Fortunately the D.F.G. is well supplied with funds and can offer a scholarship for study overseas which, being tax-free, compares quite favourably with the salary a German doctor would earn at home. I was told that any German doctor with a worthwhile research programme stands a good chance of receiving a scholarship to pursue it in Britain. He receives an overseas allowance in spite of the lower cost of living in this country. He must, of course, provide a reason for choosing a laboratory in Britain rather than Germany but the officers of D.F.G. maintain that such reasons are judged fairly and without any pressure from the federal government to conserve foreign exchange. Germans who have visited Britain as students often want to return as graduates and we should see an increase in the number of German doctors opting for D.F.G. scholarships in Britain.

The facilities for short term visits to this country were not well known. Both the British Council and the Wellcome Foundation run academic link schemes which provide funds for interchange of persons, specimens, etc., between British and German departments engaged in collaborative work. Much interest was expressed in these schemes, which also deserve wider publicity.

\section{Britons in West Germany}

Though fluency in German is required for clinical work, Britons with no knowledge of German can work in research laboratories since most of the staff speak English. A British couple working at Bonn had found their total ignorance of the language no problem in the laboratory though it had made social life tough for the first few months. They were employed in established posts, not on travelling scholarships, and there is plenty of scope for this type of exchange. West German academic posts are open to non-Germans and attract applicants from Switzerland, the Low Countries, Scandinavia, and North America. So far there are few applicants from Britain but for juniors there is plenty of opportunity for private arrangements between departments in the two countries.

The newly arrived research worker would find life more expensive than in a British provincial city (perhaps $30-50 \%$ higher than in Britain), perhaps even more expensive than London, and would be hard put to it to find a meal even in a Wimpy bar much below $£ 1$. A visiting Briton will receive considerable help from the German offices of the British Council and from the German organization for welcoming foreign visitors. Each university has an Austauschführer, a senior academic charged with caring for the welfare of foreign students and visitors, and supplied with a modest entertainment allowance.

\section{Conclusions}

West German medicine is going through exciting times, with a complete revision of the educational programme and examination system and a rapid expansion of research facilities. There is a genuine interest in closer contact with Britain, not at the jamboree level associated with international congresses, but in patterns leading to lasting friendship and scientific collaboration. Moreover, there are growing opportunities for this type of contact. Germany offers attractive opportunities for Britons in laboratory research and there is no shortage of young Germans who would like to benefit from British scientists in those fields in which we excel or to use our facilities for clinical research and training-though salary differentials do hinder this limb of the exchange.

Britons should not be discouraged from considering Germany for postgraduate training or research because of their linguistic impotence. Nonetheless, if we are serious about drawing closer to our largest Common Market partner, we must do something about our educational system. My own children are offered the same fare as I was in the second world war: compulsory French at 9, Latin at 10, optional German at 13. We could take one tentative step into the 20 th century if we persuaded the public schools to substitute German for Latin in the Common Entrance examination.

\section{References}

1 Dollery, C. T., and Burn, J. I., British Medical fournal, 1973, 1, 601. - Science in the Federal Republic of Germany; Organization and Promotion. Bonn, Deutscher Akademischer Austauschdienst, 1972.

3 D.F.G. Organization and Function, 2nd. edn. Wiesbaden, German Research Society, Steiner Verlag, 1972. 